\title{
Tonic Nanomolar Dopamine Enables an Activity-Dependent Phase Recovery Mechanism That Persistently Alters the Maximal Conductance of the Hyperpolarization-Activated Current in a Rhythmically Active Neuron
}

\author{
Edmund W. Rodgers, ${ }^{1}$ Jing Jing Fu, ${ }^{1}$ Wulf-Dieter C. Krenz, ${ }^{1}$ and Deborah J. Baro ${ }^{1,2}$ \\ ${ }^{1}$ Department of Biology and ${ }^{2}$ Neuroscience Institute, Georgia State University, Atlanta, Georgia 30303
}

\begin{abstract}
The phases at which network neurons fire in rhythmic motor outputs are critically important for the proper generation of motor behaviors. The pyloric network in the crustacean stomatogastric ganglion generates a rhythmic motor output wherein neuronal phase relationships are remarkably invariant across individuals and throughout lifetimes. The mechanisms for maintaining these robust phase relationships over the long-term are not well described. Here we show that tonic nanomolar dopamine (DA) acts at type $1 \mathrm{DA}$ receptors (D1Rs) to enable an activity-dependent mechanism that can contribute to phase maintenance in the lateral pyloric (LP) neuron. The LP displays continuous rhythmic bursting. The activity-dependent mechanism was triggered by a prolonged decrease in LP burst duration, and it generated a persistent increase in the maximal conductance $\left(G_{\max }\right)$ of the LP hyperpolarization-activated current $\left(I_{\mathrm{h}}\right)$, but only in the presence of steady-state DA. Interestingly, micromolar DA produces an LP phase advance accompanied by a decrease in LP burst duration that abolishes normal LP network function. During a $1 \mathrm{~h}$ application of micromolar DA, LP phase recovered over tens of minutes because, the activity-dependent mechanism enabled by steady-state DA was triggered by the micromolar DA-induced decrease in LP burst duration. Presumably, this mechanism restored normal LP network function. These data suggest steady-state DA may enable homeostatic mechanisms that maintain motor network output during protracted neuromodulation. This DA-enabled, activitydependent mechanism to preserve phase may be broadly relevant, as diminished dopaminergic tone has recently been shown to reduce $I_{\mathrm{h}}$ in rhythmically active neurons in the mammalian brain.
\end{abstract}

\section{Introduction}

The timing of neuronal firing is critical for many processes. An animal's location is coded by the phase of hippocampal neuron firing relative to the theta oscillation (Burgess et al., 2007). Human memory formation may depend upon coordinating neuronal spiking with local oscillations (Rutishauser et al., 2010). Changing the phase of neuronal firing in a motor circuit can change the ensuing motor behavior. In Aplysia the same feeding circuit can generate opposing ingestive versus egestive behaviors by switching the phase of the $\mathrm{B} 8$ motorneuron relative to other circuit neurons (Jing and Weiss, 2002). In the leech, the phasing among network neurons determines whether segmental contractions of the heart tubes are synchronous or peristaltic (Weaver et al., 2010).

A large literature suggests that neuronal firing phase can be modulated on multiple time scales. Modulatory systems use volume transmission that comprises both phasic micromolar and tonic nanomolar components (Zoli et al., 1998; Fuxe et al., 2010;

Received July 23, 2011; revised Sept. 14, 2011; accepted Sept. 18, 2011.

Author contributions: E.W.R., W.-D.C.K., and D.J.B. designed research; E.W.R., J.J.F., and W.-D.C.K. performed research; E.W.R., J.J.F., W.-D.C.K., and D.J.B. analyzed data; E.W.R., W.-D.C.K., and D.J.B. wrote the paper.

This work was supported by NIH Grant DA024039 to D.J.B. We thank Tim Dever for excellent technical assistance. Correspondence should be addressed to Deborah J. Baro at the above address. E-mail: dbaro@gsu.edu.

DOI:10.1523/JNEUROSCI.3770-11.2011

Copyright $\odot 2011$ the authors $\quad 0270-6474 / 11 / 3116387-11 \$ 15.00 / 0$
Oginsky et al., 2010). Phasic and tonic dopamine (DA) transmissions have distinct functions (Schultz, 2007): phasic release encodes temporally relevant information and modifies neuronal function on a moment-to-moment basis, while steady-state or tonic DA in the extracellular space is thought to enable motor and cognitive processes. Tonic nanomolar DA can act through translation-dependent mechanisms to persistently regulate the voltage-gated transient potassium current $\left(I_{\mathrm{A}}\right)$ in an activityindependent fashion (Rodgers et al., 2011). A recent study showed that diminished dopaminergic tone in mouse models of Parkinson's disease caused a loss of pacemaker activity and a reduction in $I_{\mathrm{h}}$ in globus pallidus neurons (Chan et al., 2011). Here we used a small motor circuit with well defined neuronal phase relationships underpinned in part, by $I_{\mathrm{A}}$ and $I_{\mathrm{h}}$, to examine the long-term effects of steady-state DA on neuronal firing phase.

The pyloric circuit in the stomatogastric nervous system of the spiny lobster, Panulirus interruptus, is a 14 neuron recurrent inhibitory circuit that produces a robust triphasic motor output (Fig. 1; Stein, 2009). All six pyloric cell types show rhythmic, $\sim 20$ $\mathrm{mV}$ oscillations in membrane potential accompanied by bursts of action potentials on the depolarized plateau (Fig. $1 B$ ). Each pyloric cell type bursts at a specific phase in the motor output.

Neuronal firing phase is critical to a neuron's function within the pyloric network. For example, the lateral pyloric (LP) neuron 
normally functions to set the upper limit on pyloric cycle frequency by directly inhibiting the pacemaker (Weaver and Hooper, 2003). However, the effect of LP inhibition is phase dependent. LP can advance or delay the pacemaker, depending upon when LP inhibition occurs during the pacemaker oscillation (Thirumalai et al., 2006). Thus, LP firing phase determines its function within the network. It was previously shown that a $10 \mathrm{~min}$ exposure to micromolar DA disrupted normal LP function by distorting the phase relationship between LP and the pacemaker (Johnson et al., 2011). In contrast, population studies demonstrated that phase relationships were largely invariant between individuals and over their lifetimes $\mathrm{Bu}-$ cher et al., 2005). How are these disparate findings reconciled? The data presented here suggest that dopaminergic tone enables homeostatic mechanisms that act over tens of minutes to preserve motor network output during protracted exposure to micromolar DA.

\section{Materials and Methods}

Animals. California spiny lobsters, Panulirus interruptus, were purchased from Don Tomlinson Commercial Fishing, Catalina Offshore Products, and Marinus Scientific and housed in saltwater aquaria at Georgia State University (Atlanta, GA). Animals of both sexes were used in these experiments.

Stomatogastric nervous system (STNS) dissection, cell identification, extracellular recordings and motor pattern analyses. Lobsters were anesthetized on ice for at least $30 \mathrm{~min}$, followed by STNS dissection, as previously described (Selverston et al., 1976). The STNS was pinned in a Sylgard-lined dish (Fig. 1). The stomatogastric ganglion (STG) was desheathed, and during this process a portion of the juxtaposed stomatogastric nerve $(s t n)$ was also desheathed. A Vaseline well was constructed around the STG and the juxtaposed $s t n$ and dorsal ventricular nerve $(d v n)$. The well was continuously superfused for the remainder of the experiment. Using a Dynamax peristaltic pump (Rainin), the STG was superfused with Panulirus saline [containing, in mm: $479 \mathrm{NaCl}, 12.8 \mathrm{KCl}, 13.7 \mathrm{CaCl}_{2}, 39$ $\mathrm{Na}_{2} \mathrm{SO}_{4}, 10 \mathrm{MgSO}_{4}, 2$ glucose, 4.99 HEPES, 5 TES $(N-$ [tris(hydroxymethyl)methyl]-2-aminoethanesulfonic acid, 2-[(2hydroxy-1,1-bis(hydroxymethyl)ethyl)amino] ethanesulfonic acid), $\mathrm{pH}$ 7.4]. Temperature was continuously monitored with a miniature probe inside the well. Temperatures changed by $<1^{\circ} \mathrm{C}$ throughout the course of the day (the change ranged from 0.1 to $0.9^{\circ} \mathrm{C}$ on any given day), and by only $3^{\circ} \mathrm{C}$ across all experiments $\left(19-22^{\circ} \mathrm{C}\right)$.

Cells were identified by combining standard intracellular and extracellular recording techniques. Intracellular somatic LP recordings were obtained using 20-40 M $\Omega$ glass microelectrodes filled with $3 \mathrm{M} \mathrm{KCl}$ connected to Axoclamp 2B or 900A amplifiers (Molecular Devices). Extracellular recordings of identified motor neurons were obtained using a model 1700 differential AC amplifier (A-M Systems) and stainless steel pin electrodes. LP neurons were identified by their distinct waveforms, the timing of their voltage oscillations, and correlation of spikes on the extracellular and intracellular recordings.

\section{B Motor output}

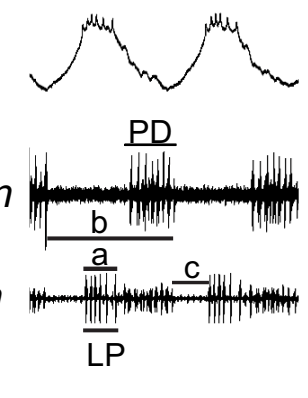

D Experimental time line
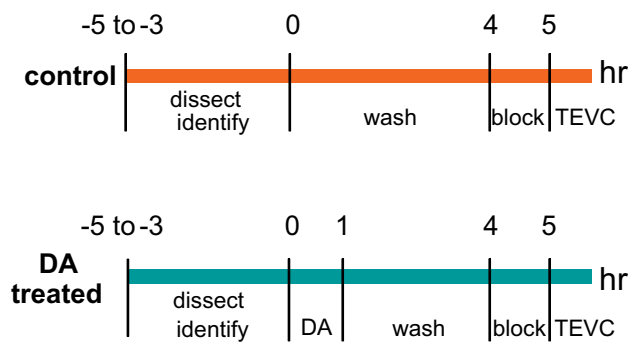

Figure 1. Experimental preparation and protocol. $\boldsymbol{A}$, Diagram of the dissected STNS pinned in a dish with a Vaseline well (gray, sing (1) $\boldsymbol{B}$, The spontaneous motor output of the pyloric network. Top trace is a representative LP intracellular recording STG. The Ivn contains several axons including those from the LP, PD and PY neurons, whose spikes are seen on the traces.

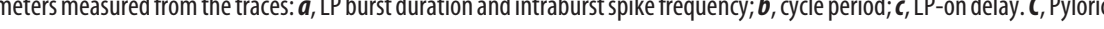
neuron and 8 PY cells. Filled circles represent inhibitory chemical synapses (PD, acetylcholine; all others, glutamate). Resistors wash with Panulirus saline. At $t=4 \mathrm{~h}$ a sucrose block was applied to the stn and the STG was superfused with blocking saline for $1 \mathrm{~h}$, after which TEVC was used to measure LP currents. Both $/ v n$ and $p d n$ recordings were maintained from $t=0-4 \mathrm{~h}$.

Pyloric activity was recorded with Axoscope v8.2 software (Molecular Devices) via extracellular electrodes on the lateral ventricular nerve $(l v n)$ and pyloric dilator nerve $(p d n)$. Extracellular recordings were analyzed using DataView v6.3.2 (Heitler, 2009) to determine cycle period and frequency, spikes per burst, burst duration, duty cycle, intraburst spike frequency, LP-on delay, and LP phase. Reported values for all parameters represent a 10 cycle average. By convention the first spike in the pyloric dilator neuron (PD) defines the beginning of a pyloric cycle, and the phasing of pyloric neurons is determined relative to the start of the cycle. Since we were interested in recovery mechanisms intrinsic to LP, we broke with convention and used the last spike in PD to define the beginning of the cycle, because tonic DA can cause persistent changes in PD ionic conductances (Rodgers et al., 2011). One cycle period was therefore defined as the last spike in one PD burst to the last spike in the next PD burst (Fig. $1 B$ ). The LP-on phase, which defined the point in the cycle where LP began firing, was measured as the time between the last spike in PD and the first spike in LP (termed LP-on delay; Fig. $1 B$ ) divided by cycle period. LP duty cycle was calculated as LP burst duration divided by cycle period. Intraburst spike frequency was calculated as LP spikes per burst divided by LP burst duration. 
A Comparison across groups

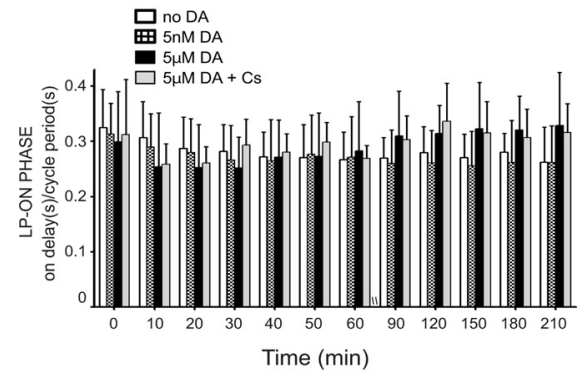

C

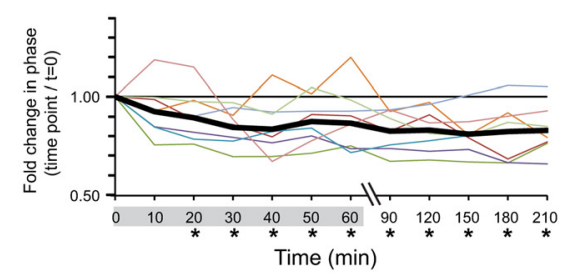

E Cs dose response curve

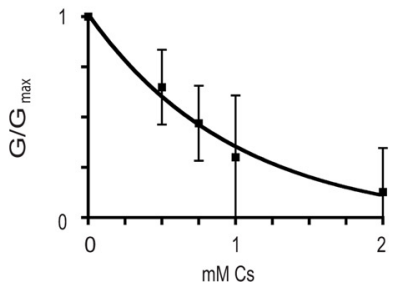

B

Control

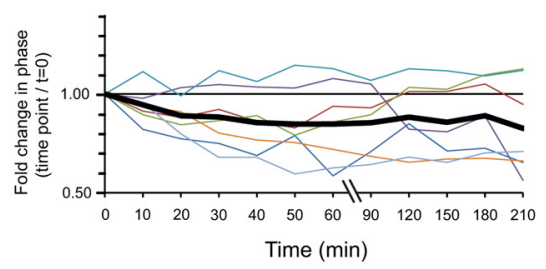

D

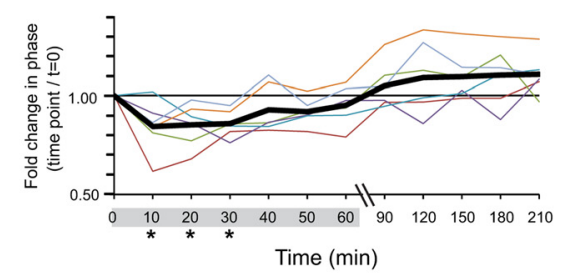

$F$

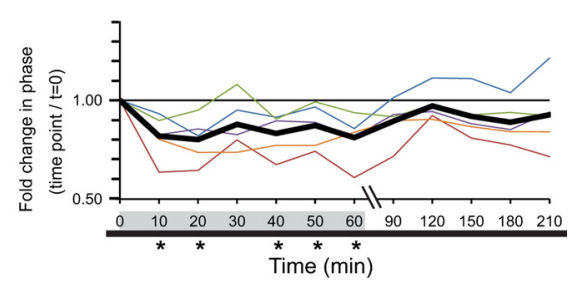

Figure 2. Tonic application of $5 \mu \mathrm{m}$ DA triggered a slow phase recovery mechanism. The experiments in Figure 1D were performed for control, $5 \mathrm{~nm}$, and $5 \mu \mathrm{m}$ DA treatment groups; and LP-on phase was measured every 10 min for the first hour and every 30 min thereafter. Some $5 \mu \mathrm{m}$ DA preparations also received $0.5 \mathrm{~mm}$ Cs from $t=0-4 \mathrm{~h}$. $A$, There are no significant differences in LP-on phase between treatment groups. LP-on phase (mean + SD) is plotted over time for the four treatment groups. Vertical slashes on the $x$-axis indicate a change in scale. There were no significant differences between treatment groups at any time point examined (two-way ANOVA: treatment, $F_{(3,253)}=0.2340, p=0.8718$; time, $F_{(11,253)}=5.020, p<0.0001$ (see $B-E)$; interaction, $\left.F_{(33,253)}=3.531, p<0.0001\right)$. $\boldsymbol{B}-\boldsymbol{D}$, There are significant changes in LP-on phase over time within treatment groups. Fold changes in LP-on phase are plotted over time for a given treatment group. Each thin line represents the fold change $(t / t=0)$ in LP-on phase throughout one experiment. The thick black line in each graph represents the average fold change for the treatment group. Highlighted time points indicate the period of DA application. Asterisks indicate significantly different from $t=$ 0 , as determined using repeated-measures ANOVAs with Dunnett's post hoc tests that compares all time points to $t=0$. ( $\boldsymbol{B}$, control: $\left.F_{(11,6)}=1.926, p=0.0515 ; \boldsymbol{C}, 5 \mathrm{~nm} \mathrm{DA:} F_{(11,8)}=4.253, p<0.0001 ; \boldsymbol{D}, 5 \mu \mathrm{m} \mathrm{DA:} F_{(11,5)}=9.72, p<0.0001\right) . \boldsymbol{E}, \mathrm{A}(\mathrm{s}$ dose-response curve showing the fraction of $I_{h}$ remaining as increasing concentrations of $C s$ were sequentially superfused into the Vaseline well surrounding the STG. $I_{\mathrm{h}} G_{\max }$ was measured using TEVC $10 \mathrm{~min}$ after a given $(s$ concentration entered the bath. Fraction of $I_{\mathrm{h}}$ remaining was determined to be: $\left(G_{\max }\right.$ in $x \mathrm{~mm}(\mathrm{~S}) \div\left(G_{\max }\right.$ in $\left.0 \mathrm{Cs}\right)$. Each data point represents the mean and SD for 3 experiments. $\boldsymbol{F}, \mathrm{Cs}$ prevents LP-on phase recovery. Fold changes are plotted over time for the $5 \mu \mathrm{m}$ DA treatment group that also received $0.5 \mathrm{~mm}$ (s from $t=0-4 \mathrm{~h}$ (black line under $x$-axis). * Significantly different from $t=0$ using a repeated-measures ANOVA with a Dunnett's post hoc test $\left(F_{(11,4)}=4.2, p=0.0003\right)$.

Experimental design. After STNS dissection and cell identification, we performed the following experimental protocol: DA ( $5 \mathrm{nM}$ or $5 \mu \mathrm{M}$ ) was applied to the STG for $1 \mathrm{~h}$ (Fig. $1 \mathrm{D}$ ). Control preparations received saline during this time. In both DA-treated and control conditions, this was followed by a $3 \mathrm{~h}$ saline wash, unless otherwise indicated. After $4 \mathrm{~h}$, descending input was removed with a sucrose block on the stn and the ganglion was prepared for two-electrode voltage clamp (TEVC) to measure $I_{\mathrm{h}}$, as described below.

Manipulations to study activity dependence. We used two methods to study the role of LP activity in phase recovery. First, 100 nM tetrodotoxin (TTX) was added to the perfusate from $t=-10 \mathrm{~min}$ to $1 \mathrm{~h}$ (Fig. $1 D$ ). This blocked all action potentials and slow membrane oscillations. A $1 \mathrm{~h}$ TTX (or TTX + DA) administration was followed by a $3 \mathrm{~h}$ wash with Panulirus saline. Preparations that did not recover a pyloric rhythm by the end of the $3 \mathrm{~h}$ wash were excluded from the analysis. In 19 of 21 cases, rhythmic activity resumed after a $1 \mathrm{~h}$ wash, and 3 experiments were excluded. Second, to either prevent decreases in LP burst duration in 5 $\mu \mathrm{M} \mathrm{DA}$, or to induce decreases in burst duration in control and $5 \mathrm{~nm} \mathrm{DA}$, positive (0.7-2.5 $\mathrm{nA})$ or negative $(0.5-2 \mathrm{nA})$ DC current was injected into the LP cell, respectively, for $1 \mathrm{~h}$. We used the minimum amount of depolarizing current required to prevent a change in burst duration and the minimum amount of hyperpolarizing current required to induce a $20-$ $30 \%$ decrease in burst duration. The necessary amount of current was determined empirically just before the start of the experiment (i.e., from $t=-15-0 \mathrm{~min}$; Fig. $1 D$ ).

TEVC. A portion of the stomatogastric nerve was desheathed and isolated in a second Vaseline well. Descending inputs to the STG were removed with a sucrose block applied into this well for $1 \mathrm{~h}$. During the same time the STG was continuously superfused with Panulirus saline containing picrotoxin $(1 \mu \mathrm{M})$ to block glutamatergic synaptic inputs. Voltage-dependent ion channel blockers were also added to the perfusate: TTX (100 nM, $I_{\mathrm{Na}}$ ), tetraethylammonium $\left(20 \mathrm{~mm}, I_{\mathrm{K}(\mathrm{V})}\right.$ and $\left.I_{\mathrm{K}(\mathrm{Ca})}\right)$, and cadmium chloride $\left(\mathrm{CdCl}_{2}, 200 \mu \mathrm{M}, I_{\mathrm{Ca}}\right)$. TTX was from Tocris Bioscience, all other reagents were from Sigma. For TEVC the LP neuron was impaled with two micropipettes (7-10 M $\Omega$ when filled with $3 \mathrm{M} \mathrm{KCl}$ ) connected to Axoclamp 2B or 900A amplifiers (Molecular Devices). Using Clampex software (Molecular Devices, v.8.2) $\mathrm{LP}$ was clamped to a $-50 \mathrm{mV}$ holding potential. $I_{\mathrm{h}}$ was then measured using a series of $4 \mathrm{~s}$ hyperpolarizing voltage steps, from -60 to $-120 \mathrm{mV}$ in $10 \mathrm{mV}$ increments. $I_{\mathrm{h}}$ was measured by subtracting the initial fast leak current step from the slowly developing peak of $I_{\mathrm{h}}$ at the end of each negative voltage step. Current peaks were converted to conductance $(G=$ $I_{\text {peak }} /\left(V_{\mathrm{m}}-V_{\text {rev }}\right)$ and fit to a first-order Boltzmann equation. $V_{\text {rev }} I_{\mathrm{h}}=-35 \mathrm{mV}$ (Kiehn and Harris-Warrick, 1992).

Statistical analysis. Data were checked for normal distribution and analyzed using parametric statistical tests with Prism software package v5.01 (GraphPad). Significance was set at $p<0.05$ in all cases. Means are followed by SDs. Individual samples that were $>2$ SDs from the mean were excluded from the analyses after determining the mean. ANOVAs are followed by post hoc tests that make all possible comparisons between columns (Tukey's) or that compare all columns to $t=0$ (Dunnett's).

\section{Results}

\section{A slow phase recovery mechanism}

The pyloric network in the crustacean STG is a small central pattern generator that controls rhythmic movements of the foregut (Fig. 1). This 14 neuron network produces a triphasic motor output (Fig. $1 B$ ). The electrically coupled pacemaker kernel, composed of one anterior burster and two PD neurons, rhythmically inhibits follower neurons, including the single LP and the eight pyloric constrictor neurons (PYs). Using the conventional definition of phase (Bucher et al., 2005), PD firing represents phase 1 of the triphasic output. Upon removal of pacemaker inhibition, LP and PY neurons rebound to fire a burst of action potentials on a depolarized plateau. Relative to PY, LP has a faster rate of postinhibitory rebound (PIR) and fires first to strongly inhibit PD and weakly inhibit PY (phase 2). PY subsequently fires 
on rebound from pacemaker inhibition and inhibits LP (phase 3 ), thereby terminating the LP burst and LP inhibition of the pacemaker, causing the cycle to begin again. Thus, the order of neuronal firing is consistently PD-LP-PY, and the delay in firing between PD-LP and PD-PY scales with cycle frequency.

Within the network, LP functions to slow cycle frequency by directly inhibiting the pacemaker kernel (Weaver and Hooper, 2003). A $10 \mathrm{~min}$ bath application of $100 \mu \mathrm{M}$ DA phase advanced LP, reduced LP burst duration and increased pacemaker cycle frequency (Flamm and Harris-Warrick, 1986a). Under these conditions the phase of LP was shifted relative to pacemaker kernel, and LP synaptic inhibition was ineffective because it occurred when the pacemaker kernel was in the refractory period of its oscillation (Johnson et al., 2011). LP lost its functionality in this situation; it could no longer slow cycle frequency, so the upper limit on network cycle frequency vanished. Given that this network is built to maintain phase (Bucher et al., 2005), we were curious as to what would happen if the experiment continued beyond $10 \mathrm{~min}$.

To induce a persistent perturbation in LP phase, we challenged the pyloric circuit with tonic DA applications. The experimental design is shown in Figure 1 and described in Materials and Methods: The STNS was dissected, the STG was superfused with DA ( $5 \mathrm{nM}$ or $5 \mu \mathrm{M}$, DA-treated) or Panulirus saline (control) for $1 \mathrm{~h}$ followed by a 3 h wash with Panulirus saline. Extracellular recordings from the $p d n$ and lvn were maintained throughout this portion of the experiment. After the $4 \mathrm{~h}$ treatment, descending input was blocked and the STG was superfused with blocking saline for $1 \mathrm{~h}$, and then LP currents were measured with TEVC. Using the extracellular recordings we measured the phase of LP every 10 min during the first hour and every $30 \mathrm{~min}$ thereafter throughout the $3 \mathrm{~h}$ wash. Changes in LP-on phase over the course of the experiments are shown in Figure 2. A two-way ANOVA indicated there were no significant differences in LP-on phase between treatment groups at any time point examined (Fig. 2A); however, there were significant changes over time within DA treatment groups (Figs. $2 B-D$ ). There was not a significant change in LP phase in the control treatment group; however, there was an overall trend toward phase advancement (Fig. $2 B$ ). The $5 \mathrm{~nm}$ DA preparations displayed a significant, sustained phase advance throughout the experiment (Fig. 2C). The $5 \mu \mathrm{M} \mathrm{DA}$ treatment group also showed a significant phase advance by 10

\section{A LP I $\mathrm{h}$ current traces}

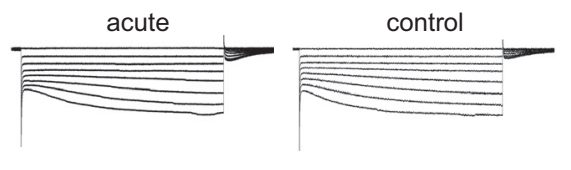

B LP Ih Voltage Dependence

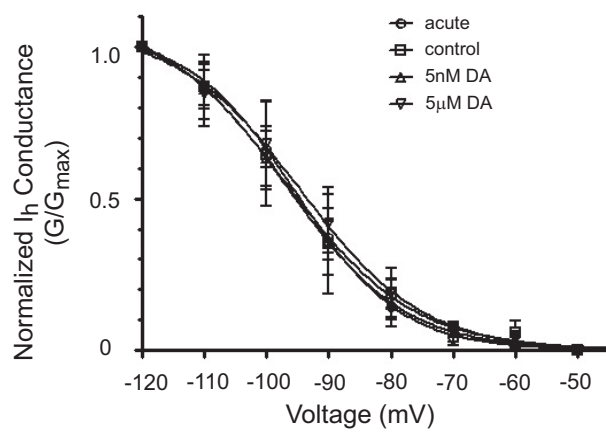

$5 \mu \mathrm{M}$ DA

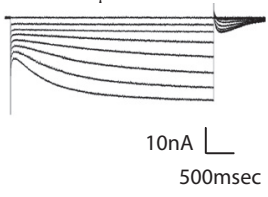

C LP Ih Gmax

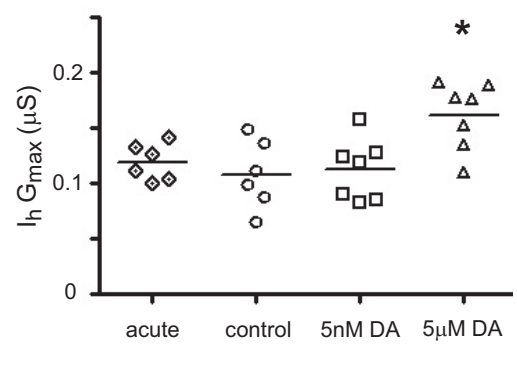

Figure 3. $5 \mu \mathrm{m}$ DA caused a persistent increase in $\mathrm{LP} /_{\mathrm{h}} G_{\max }$ by the end of the experiment diagrammed in Figure $1 D . A$, Typical $\mathrm{LP} I_{\mathrm{h}}$ current traces elicited by a series of hyperpolarizing steps using TEVC. Acute measures were obtained by blocking from $t=$ $0-1 \mathrm{~h}$ followed by TEVC. Control and DA treatment groups were obtained as diagrammed in Figure $1 D$. B, Plots of normalized voltage dependence of activation for $L P I_{h}$ are not significantly different across the four treatment groups. Using TEVC, the $L P$ was held at $-50 \mathrm{mV}$ and subjected to a series of hyperpolarizing test pulses. Conductance was obtained for each test pulse and normalized by the conductance for the $-120 \mathrm{mV}$ test pulse. Each data point represents the mean $\pm S D$ for $n \geq 6$. C, Plots of $L P I_{h}$ $G_{\max }$ for the four experimental preparations. Each symbol represents the $L P I_{h} G_{\max }$ measured with TEVC at the end of one experiment. Horizontal line represents the mean for the group. *Significantly different from acute, control and $5 \mathrm{~nm}$ DA as determined using a one-way ANOVA with Tukey's post hoc test: $F_{(3,25)}=5.619, p=0.0051$. Acute, control, and $5 \mathrm{~nm} \mathrm{DA} \mathrm{treatment}$ groups were not significantly different from one another (Tukey's, $p>0.05$ ).
A Comparison across groups for each time point
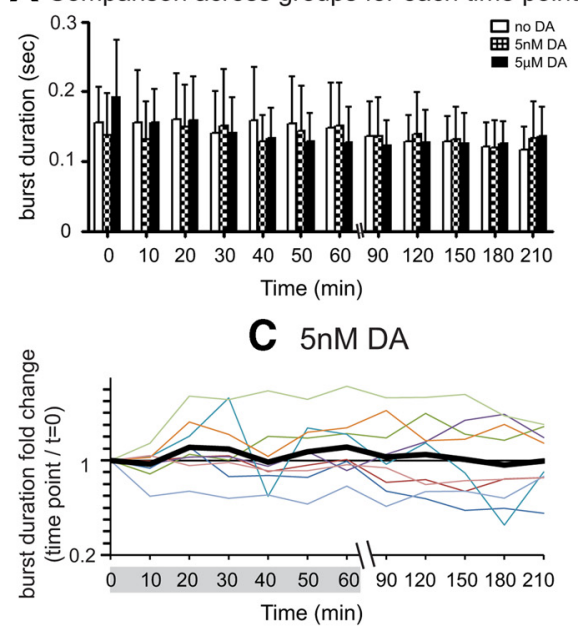

B Control
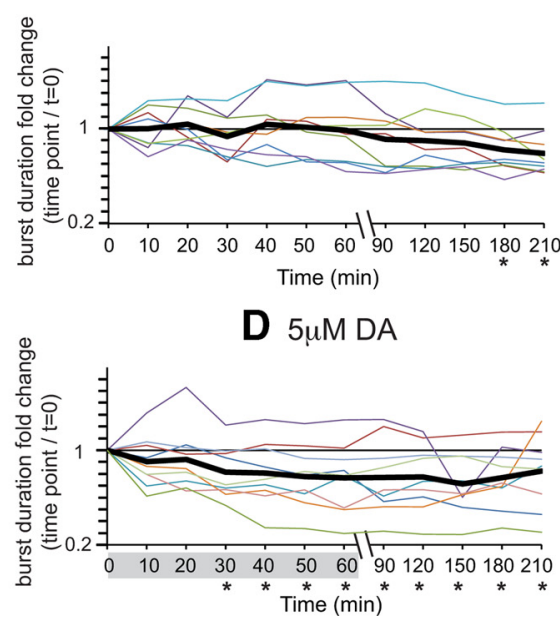

Figure 4. LP burst duration significantly decreased during the first hour of the experiment diagrammed in Figure $1 D$ for $5 \mu \mathrm{m}$, but not control or $5 \mathrm{~nm}$ DA preparations. A, Plot of LP burst duration (mean + SD) for the 3 treatment groups at 10 min intervals during the first hour of the experiment, and every 30 min thereafter. Vertical slashes on the $x$-axis indicate a change in scale. There were no significant differences between treatment groups at any time point (two-way ANOVA: treatment, $F_{(2,253)}=0.008879, p=0.9912 ;$ time, $F_{(11,253)}=3.888, p<$ 0.0001 (see $\boldsymbol{B}-\boldsymbol{D}$ ); interaction, $F_{(22,253)}=1.794, p=0.0178$ ). $\boldsymbol{B}-\boldsymbol{D}$, Fold changes in burst duration over time within a treatment group. Each thin line represents one experiment and is a plot of the fold change $(t / t=0)$ in $L P$ burst duration throughout the experiment diagrammed in Figure 1D. Thick black lines represent average fold changes. Highlighted data points represent the period of DA application. *Significantly different from $t=0$, as determined using repeated-measures ANOVAs with Dunnett's post hoc tests that compare all time points to $t=0\left(B\right.$, control: $F_{(11,8)}=3.723, p=0.0002 ; C, 5$ nmDA: $\left.F_{(11,8)}=1.017, p=0.4386 ; \boldsymbol{D}, 5 \mu \mathrm{mDA}: F_{(11,7)}=3.235, p=0.0011\right)$. min, but phase slowly recovered over the next $60 \mathrm{~min}$, despite the continued presence of $5 \mu \mathrm{M}$ DA (Fig. 2 D). Upon DA washout average LP-on phase became delayed, suggesting recovery induced a persistent change and was not simply due to recep- 
A Comparison across groups for each time point
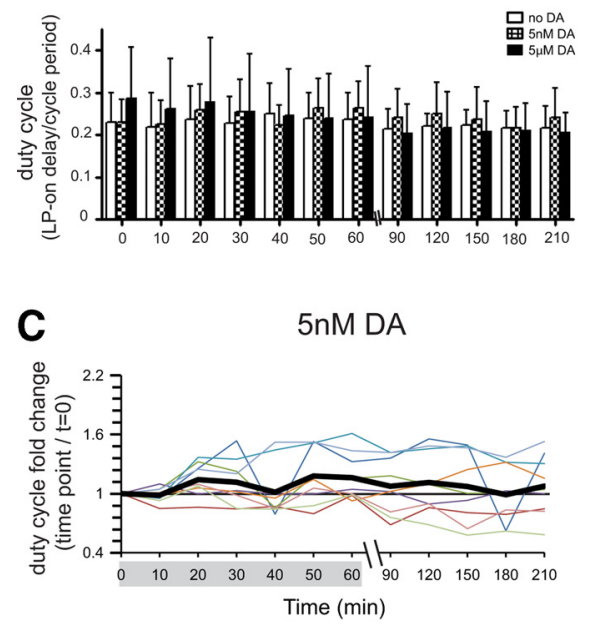

\section{B \\ B}

Control

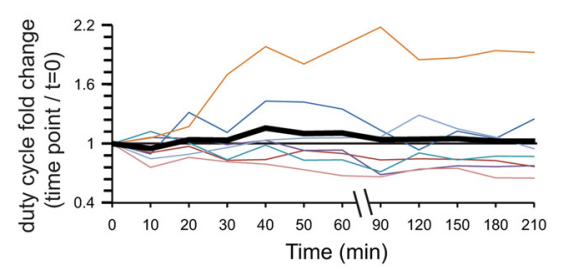

D $5 \mu \mathrm{M} D A$

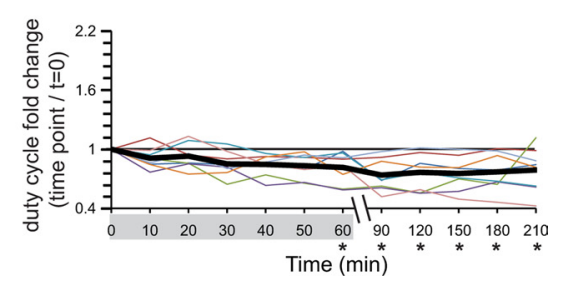

Figure 5. Fold changes in LP duty cycle during the experiments illustrated in Figure 1D.A, LP duty cycle (mean + SD) is plotted every $10 \mathrm{~min}$ for the first hour of the experiment and every $30 \mathrm{~min}$ thereafter. Vertical slashes on the $x$-axis indicate a change in scale. There were no significant differences in duty cycle between the three treatment groups at any time point examined (twoway ANOVA: treatment, $F_{(2,231)}=0.09067, p=0.9137 ;$ time, $F_{(11,231)}=2.826, p=0.0018$; interaction, $F_{(22,231)}=1.554, p=$ $0.0587) . \boldsymbol{B}-\boldsymbol{D}$, Fold changes in duty cycle over time within each treatment group. Each thin line represents one experiment and is a plot of the fold change $(t / t=0)$ in LP duty cycle throughout the experiment diagrammed in Figure $1 D$. Thick black lines represent average fold changes. Highlighted data points represent the period of DA application. * Significantly different from control as determined using repeated-measures ANOVAs with Dunnett's post hoc tests that compare all time points to $t=0(\boldsymbol{B}$, control: $\left.F_{(11,7)}=0.8325, p=0.6084 ; C, 5 \mathrm{~nm} \mathrm{DA}: F_{(11,9)}=1.918, p=0.0458 ; D, 5 \mu \mathrm{m} \mathrm{DA:} F_{(11,7)}=3.265, p=0.0011\right)$.
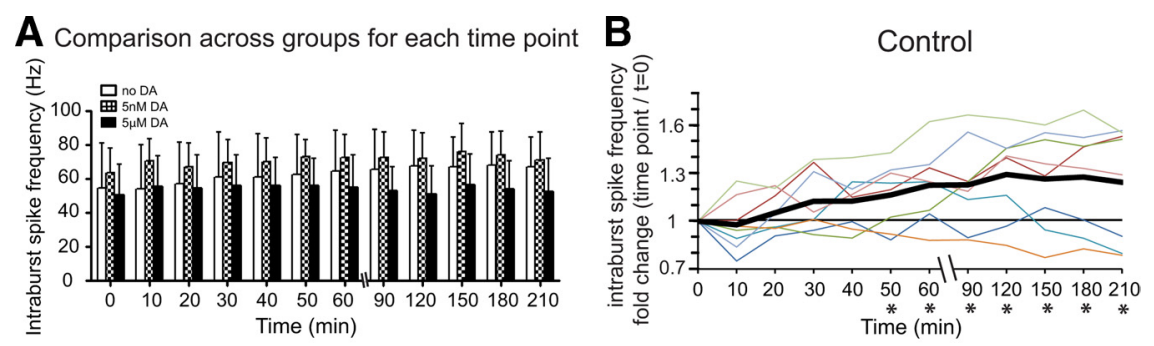

C

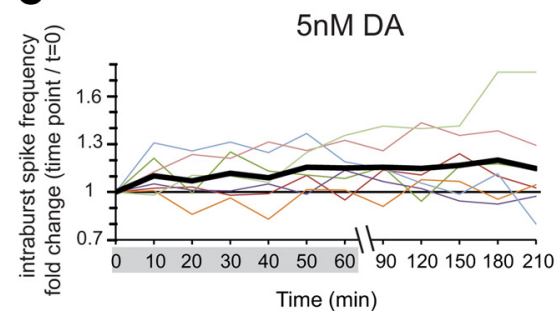

D

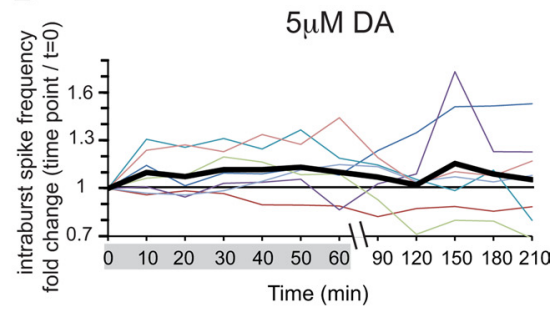

Figure 6. LP intraburst spike frequency significantly increased during the first hour of the experiment illustrated in Figure $1 D$ for control but not $5 \mathrm{~nm}$ or $5 \mu \mathrm{m}$ DA preparations. A, LP intraburst spike frequency (mean + SD) is plotted for the three treatment groups every $10 \mathrm{~min}$ for the first hour of the experiment and every $30 \mathrm{~min}$ thereafter. Vertical slashes on the $x$-axis indicate a change in scale. There were no significant differences between the three treatment groups at any given time point (two-way ANOVA: treatment, $F_{(2,220)}=1.574, p=0.2319$; time, $F_{(11,220)}=2.924, p=0.0013$ (see $\left.\boldsymbol{B}-\boldsymbol{D}\right)$; interaction, $F_{(22,220)}=1.039, p=$ $0.4184)$. $\boldsymbol{B}-\boldsymbol{D}$, Fold changes in intraburst spike frequency over time within a treatment group. Each thin line represents a plot of the fold change $(t / t=0)$ in LP intraburst spike frequency during one experiment. Thick black lines represent average fold changes. Highlighted data points represent period of DA application. *Significantly different from $t=0$ as determined using repeatedmeasures ANOVAs with Dunnett's post hoc tests that compare all time points to $t=0\left(\boldsymbol{B}\right.$, control: $F_{(11,9)}=3.690, p=0.0002 ; \boldsymbol{C}$, $\left.5 \mathrm{~nm} \mathrm{DA:} F_{(11,6)}=1.401, p=0.1935 ; D, 5 \mu \mathrm{mDA}: F_{(11,6)}=0.5352, p=0.8724\right)$.

tor desensitization. In the $5 \mu \mathrm{M}$ DA treatment group, the LP phase advance at 10 min must have been at least partially due to previously demonstrated DA-induced shifts in LP $I_{\mathrm{A}}$ and $I_{\mathrm{h}}$ voltage dependencies causing $I_{\mathrm{A}}$ to be reduced and $I_{\mathrm{h}}$ to be increased (Harris-Warrick et al., 1995b). The change in LP $I_{\mathrm{A}}$ is largely responsible for the phase advance (Harris-Warrick et al., 1995b), but the threshold for this change is $\sim 1 \mu \mathrm{M}$ DA (Zhang et al., 2010); thus, it is not clear what caused the significant, persistent phase advance in the $5 \mathrm{~nm}$ DA treatment group. It may not even have been due to DA given the trend in the control preparations. Here we concentrate on the mechanism for slow phase recovery, as observed in the $5 \mu \mathrm{M}$ DA treatment group. It should be noted that LPoff phase was similarly phase-advanced in the $5 \mu \mathrm{M}$ DA, but not control or $5 \mathrm{~nm}$ DA treatment groups (repeated-measures ANOVAs: control, $F_{(5,11)}=0.7413, p=$ $0.6946 ; 5 \mathrm{nM} \mathrm{DA}, F_{(4,11)}=1.929, p=$ $0.0613 ; 5 \mu \mathrm{M} \mathrm{DA}, F_{(5,11)}=4.650, p<$ $0.0001)$.

\section{Slow phase recovery requires persistent changes in $I_{h}$}

$I_{\mathrm{h}}$ is a resonating conductance with demonstrated plasticity (Hutcheon and Yarom, 2000; Wahl-Schott and Biel, 2009). We tested $I_{\mathrm{h}}$ involvement in LP-on phase recovery by repeating the experimental paradigm shown in Figure $1 D$ for control and $5 \mu \mathrm{M}$ DA treatment groups with the inclusion of $0.5 \mathrm{~mm} \mathrm{CsCl}$ (Cs) in the perfusate from $t=$ $0-4$ h to block $\sim 30 \%$ of $I_{\mathrm{h}}$ (Fig. $2 E$ ). Adding $\mathrm{Cs}$ to the control treatment group had little effect on LP-on phase: Average changes in LP-on phase were $<10 \%$ and not statistically significant at any time point examined (repeated-measures ANOVA, $F_{(11,5)}=$ 0.5579, $p=0.8539$ ). On the other hand, adding Cs to the $5 \mu \mathrm{M}$ DA treatment group had a significant effect. While partially blocking $I_{\mathrm{h}}$ did not prevent the DA-induced LP-on phase advance, it did prevent phase recovery during DA administration (Fig. $2 F$ ). These results implied that $I_{\mathrm{h}}$ was critical to the slow phase recovery mechanism.

We next examined whether or not LP $I_{\mathrm{h}}$ was persistently altered in neurons that showed phase recovery ( $5 \mu \mathrm{M}$ DA) versus those that did not (5 nM DA and control). LP $I_{\mathrm{h}}$ was measured with TEVC at the end of the experiments diagrammed in Figure $1 D$. In addition, to obtain a baseline for comparison, in a separate series of experiments LP $I_{\mathrm{h}}$ was also measured acutely (i.e., using the diagram in Fig. $1 D$, block from $t=0-1 \mathrm{~h}$, followed by TEVC). We found that peak LP $I_{\mathrm{h}}$ was significantly increased in $5 \mu \mathrm{M}$ DA relative to acute, control and 5 nM DA treatment groups (Fig. $3 A)$. The increased peak current was not due to a change in $I_{\mathrm{h}}$ voltage dependence of activation (Fig. $3 B$ ), but to a significant, persistent increase in $L P I_{\mathrm{h}} G_{\max }$ (Fig. $3 C$ ). Average $I_{\mathrm{h}} G_{\max }$ in the $5 \mu \mathrm{M}$ DA treatment group $(0.162 \pm 0.03$ $\mu \mathrm{S})$ was increased $35 \%, 50 \%$ and $44 \%$ relative to acute $(0.119 \pm$ $0.017 \mu \mathrm{S})$, control $(0.108 \pm 0.031 \mu \mathrm{S})$, and $5 \mathrm{nM} \mathrm{DA}(0.113 \pm$ $0.027 \mu \mathrm{S})$ treatment groups, respectively. 
A decrease in burst duration is necessary for the increase in $L P I_{h} G_{\max }$ and phase recovery

We conceptualized the slow phase recovery mechanism in terms of an activitydependent homeostat (Davis, 2006). A homeostat maintains a target, in this case phase. A homeostat triggers a target recovery mechanism(s), in this case an increase in LP $I_{\mathrm{h}} G_{\mathrm{max}}$. An activity-dependent homeostat also contains a sensor that detects a change in some measure of neuronal or network activity.

To identify changes in activity that were unique to the $5 \mu \mathrm{M}$ DA treatment group during the time period for triggering phase recovery, we measured the following parameters for all treatment groups throughout the experiments diagrammed in Figure $1 D$ : LP burst duration (Fig. 4), LP duty cycle, which defines the fraction of the cycle throughout which LP is active (Fig. 5), LP intraburst spike frequency (Fig. 6) and pyloric cycle frequency (Fig. 7). Two-way ANOVAs indicated that there were no significant differences between treatment groups at any time points examined for any of these parameters (Figs. 4A, 5A, 6A, 7A). However, within group analyses revealed two distinct features that were exclusive to 5 $\mu \mathrm{M}$ DA treatment during phase recovery: a significant decrease in burst duration (Fig. $4 B-D$ ) and a significant increase in pyloric cycle frequency (Fig. $7 B-D$ ). There were no significant differences in LP duty cycles (Fig. $5 B-D$ ) or intraburst spike frequencies (Fig. $6 B-D)$ during the initiation of phase recovery $(\sim 10-40$ min) for any treatment group. However, intraburst spike frequency was significantly and persistently increased by $50 \mathrm{~min}$ in the control treatment group, while duty cycle was significantly decreased from $60 \mathrm{~min}$ through the end of the experiment in the $5 \mu \mathrm{M}$ DA treatment group.

Based on these data, we hypothesized that a decrease in LP burst duration was necessary for the increase in LP $I_{\mathrm{h}} G_{\max }$ and phase recovery. To test this hypothesis, we repeated the experiment shown in Figure $1 D$ for the $5 \mu \mathrm{M}$ DA treatment group, except we continuously injected depolarizing current into the LP from $t=0-60$ min to prevent the decrease in LP burst duration without altering the other indices of activity (Fig. 8). It is likely that DA normally decreases LP burst duration by phase advancing PY synaptic inhibition to terminate the LP burst (Selverston and Moulins, 1987; Harris-Warrick et al., 1995a). Depolarizing LP may not prevent PY phase advancement, but nevertheless prevented the decrease in LP burst duration in $5 \mu \mathrm{M}$ DA (compare Fig. $8 A$ vs $4 \mathrm{D}$ ). A comparison between $5 \mu \mathrm{M}$ DA treatment groups that did versus did not receive current injection showed that the depolarization did not appreciably alter LP duty cycle (Fig. $8 B$ vs $5 D$ ) or LP intraburst spike frequency (Fig. $8 C$ vs $6 D$ ) but may have reduced or prevented the DA-induced increase in pyloric cycle frequency (Fig. $8 D$ vs $7 D$ ). LP was similarly phase advanced in the $5 \mu \mathrm{M}$ DA treatment groups with or without current injection (Fig. $8 E$ vs $2 D$ ); however, abolishing the decrease in LP burst duration prevented phase recovery in $5 \mu \mathrm{M}$ DA (Fig. $8 E$ ) and the increase in LP $I_{\mathrm{h}} G_{\max }$ (Fig. $8 F$ ). Together these data
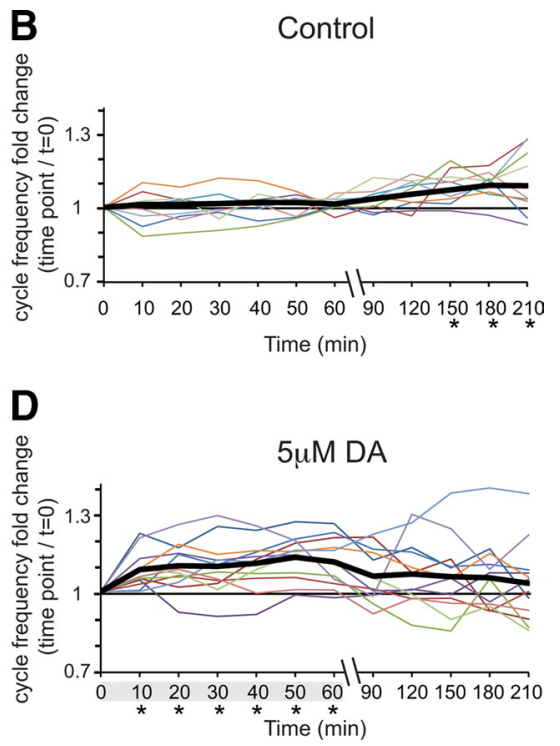

Figure 7. Pyloric cycle frequency is significantly increased during the first hour of the experiment diagrammed in Figure $1 D$ for scale. There were no significant differences between treatment groups at any time point (two-way ANOVA: treatment, $F_{(2,385)}=$ 1.283, $p=0.2900$; time, $F_{(11,385)}=2.285, p=0.0103$ (see $\left.\boldsymbol{B}-\boldsymbol{D}\right)$; interaction, $\left.F_{(22,385)}=3.829, p<0.0001\right)$. $\boldsymbol{B}-\boldsymbol{D}$, Fold changes

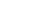

5nM DA

Time $(\min )$
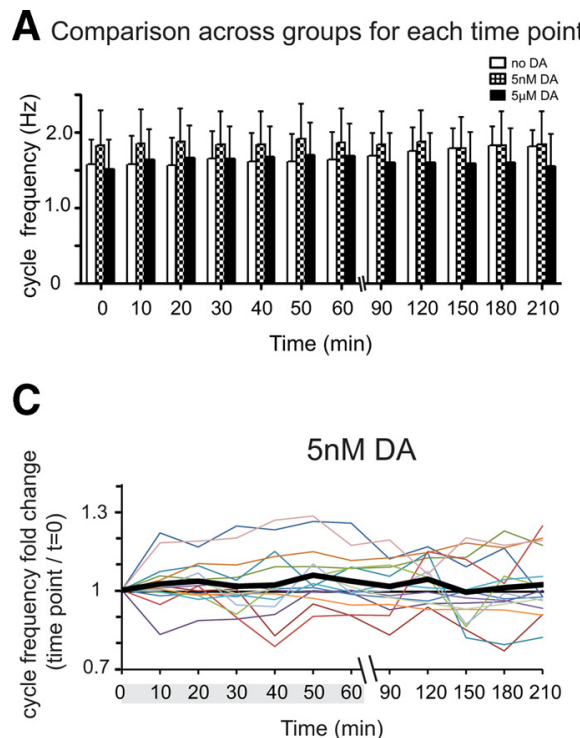
$\left.D, 5 \mu \mathrm{m} \mathrm{DA}: F_{(11,12)}=2.931, p=0.0017\right)$.

suggested that a decrease in LP burst duration was necessary for the increase in LP $I_{\mathrm{h}} G_{\max }$ and slow phase recovery.

\section{Tonic 5 nM DA permits decreases in burst duration to evoke} persistent increases in $L P I_{h} G_{\text {max }}$

The phase recovery mechanism was activity dependent, but was it also DA dependent, or was DA necessary only insofar as it caused the change in activity? To answer this question, we mimicked an extreme decrease in burst duration with TTX. The experiments shown in Figure $1 D$ were repeated for all three treatment groups, but $100 \mathrm{~nm}$ TTX was included from $t=-10 \mathrm{~min}^{-} 1 \mathrm{~h}$. If a decrease in activity alone was sufficient to increase LP $I_{\mathrm{h}} G_{\max }$, then TTX should significantly increase LP $I_{\mathrm{h}} G_{\max }$ in control and both DA-treated preparations. If both a reduction in activity and DA were absolutely required for the increase in LP $I_{\mathrm{h}} G_{\max }$, then TTX should have no effect on control, but should significantly increase LP $I_{\mathrm{h}} G_{\max }$ in $5 \mathrm{nM}$ and/or $5 \mu \mathrm{M}$ DA preparations, depending upon the DA concentration required.

TTX blocked spontaneous activity in all three treatment groups during its application and for at least $1 \mathrm{~h}$ into the wash period (Fig. 9A). Blocking activity in the control preparations did not significantly increase average LP $I_{\mathrm{h}} G_{\max }$ (Fig. 9B). On the other hand, blocking activity in the $5 \mathrm{~nm}$ DA treatment group produced a significant increase in average LP $I_{\mathrm{h}} G_{\max }$ relative to control and $5 \mathrm{~nm}$ DA preparations lacking TTX (Fig. 9B). Blocking activity in the $5 \mu \mathrm{M}$ DA treatment group did not increase the average LP $I_{\mathrm{h}} G_{\max }$ beyond that observed for $5 \mu \mathrm{M}$ DA alone (Fig. 9B).

We interpreted the data to mean that a significant, persistent increase in LP $I_{\mathrm{h}} G_{\max }$ required at least two events: a decrease in LP burst duration and an additional unknown activityindependent event(s) evoked by tonic nanomolar DA. A $1 \mathrm{~h}$ bath 
A

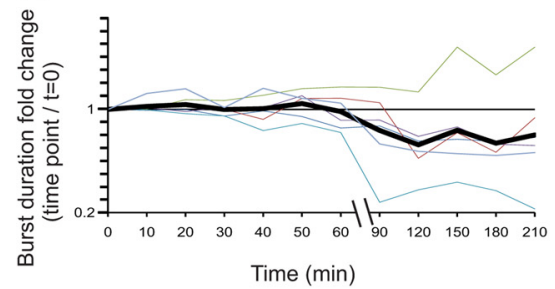

C

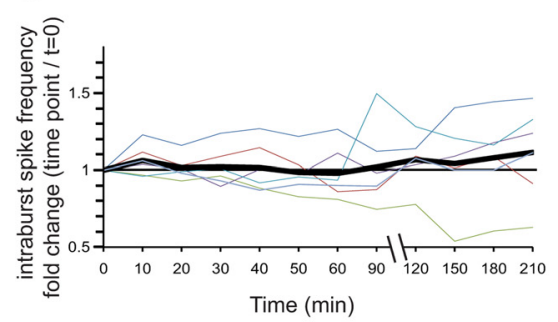

E

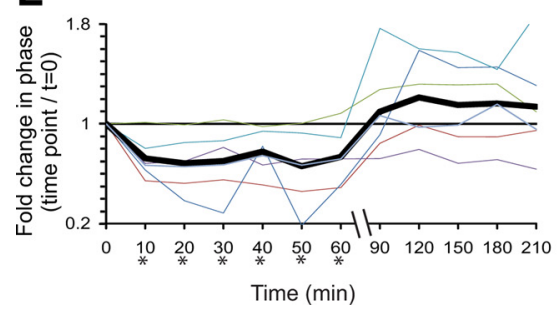

B

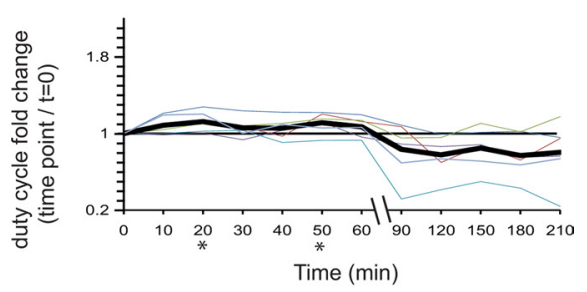

D

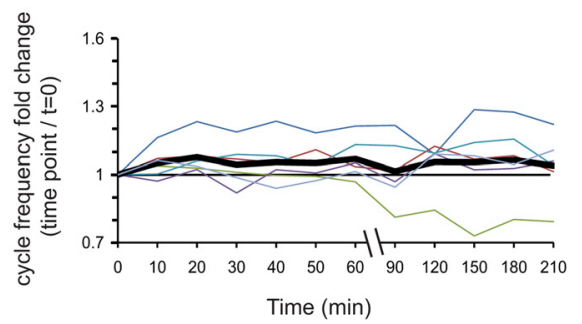

$\mathbf{F}$

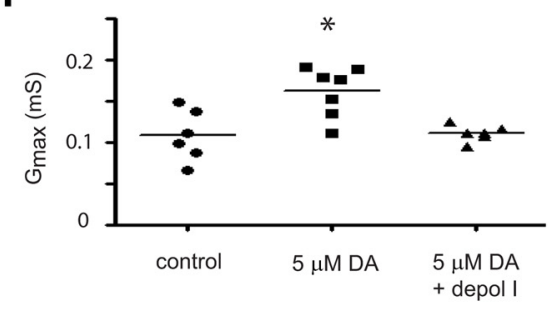

Figure 8. A reduction in LP burst duration is necessary to elicit slow phase recovery. The experiment illustrated in Figure 1D was performed for the $5 \mu \mathrm{m}$ DA treatment group with depolarizing current injections from $t=0-1 \mathrm{~h}$. $\boldsymbol{A}-\boldsymbol{E}$, The fold changes $(t / t=0)$ in LP burst duration $(\boldsymbol{A})$, LP duty cycle $(\boldsymbol{B})$, LP intraburst spike frequency $(\boldsymbol{C})$ pyloric cycle frequency $(\boldsymbol{D})$ and LP-on phase $(\boldsymbol{E})$ were plotted every $10 \mathrm{~min}$ for the first hour of the experiment and every 30 min thereafter. Vertical slashes on the $x$-axis represent a change in scale. Each thin line represents one experiment. Thick black lines represent the average fold changes. Highlighted data points represent the period of DA application. * Significantly different from $t=0$ as determined using repeated-measures ANOVAs with Dunnett's post hoc tests that compared all time points up to $t=60$ min with $t=0\left(A, \mathrm{LP}\right.$ burst duration: $F_{(11,5)}=0.7345, p=$ $0.6257 ; \boldsymbol{B}, \mathrm{LP}$ duty cycle: $F_{(11,5)}=2.453, p=0.0413 ; \boldsymbol{C}, \mathrm{LP}$ intraburst spike frequency: $F_{(11,5)}=0.7780, p=0.5936 ; \boldsymbol{D}$, pyloric cycle frequency: $F_{(11,5)}=1.758, p=0.1419 ; \boldsymbol{E}_{,} \mathrm{LP}$-on phase: $\left.F_{(11,5)}=5.188, p=0.0009\right)$. $\boldsymbol{F}$, Depolarizing current injection prevented the increase in $\mathrm{LP} I_{\mathrm{h}} G_{\max }$ in $5 \mu \mathrm{m} \mathrm{DA} . \mathrm{LP} I_{\mathrm{h}} G_{\max }$ was plotted for control, $5 \mu \mathrm{m} \mathrm{DA}$ and $5 \mu \mathrm{m} \mathrm{DA}$ with depolarizing current injection (depol I). Each symbol represents one experiment. * Significantly different from control and $5 \mu \mathrm{M}$ DA with depol I, as determined with a one-way ANOVA with Tukey post hoc test, $F_{(2,18)}=8.976, p=0.0024$.

application of $5 \mu \mathrm{M}$ DA triggered both events and a further decrease in activity did not produce a larger increase in LP $I_{\mathrm{h}} G_{\max }$ (Fig. $9 B$ ). On the other hand, a $1 \mathrm{~h}$ bath application of $5 \mathrm{~nm} \mathrm{DA}$ alone had no effect, but when combined with a decrease in activity, it produced a significant increase in LP $I_{\mathrm{h}} G_{\max }$ (Fig. 9B). Interestingly, LP $I_{\mathrm{h}} G_{\max }$ in TTX alone was not significantly different from LP $I_{\mathrm{h}} G_{\max }$ for any other treatment group (Fig. 9B), suggesting that a complete $\sim 2 \mathrm{~h}$ cessation of activity incrementally increased LP $I_{\mathrm{h}} G_{\max }$ without requiring DA.

One potential problem with these experiments is that TTX not only modifies burst duration, but also removes most modulatory input (due to action potential blockage in the terminals), and it also removes membrane potential oscillations, so the conclusion that the persistent increase in LP $I_{\mathrm{h}} G_{\max }$ requires a decrease in LP burst duration may not be correct. To address this issue, the experiments shown in Figure $1 D$ were repeated for control and 5 nM DA treatment groups, but burst duration was significantly reduced with a continuous hyperpolarizing current injection into LP from $t=0-60 \mathrm{~min}$. If our interpretation of the TTX data was correct, then LP $I_{\mathrm{h}} G_{\max }$ should be increased in the $5 \mathrm{nM}$ DA but not control treatment groups.

Hyperpolarizing current injection significantly reduced burst duration and duty cycle in both control and $5 \mathrm{~nm}$ DA treatment groups, but had no effect on their cycle or intraburst spike frequencies (Fig. 10A$D)$. The changes in burst duration induced by hyperpolarizing current injection were within the range observed for the $5 \mu \mathrm{M}$ DA treatment group (compare Fig. $10 \mathrm{~A}$ to Fig. $4 \mathrm{D}$ ). The results were consistent with our interpretation of the TTX data. Under these conditions LP $I_{\mathrm{h}}$ $G_{\max }$ was significantly increased in the 5 nM DA relative to the control treatment group (Fig. $10 \mathrm{E}$ ), despite the fact that LP activity was the same in both treatment groups (Figs. 10A-D). Notably, hyperpolarizing current injection induced a phase delay in LP (Fig. 10F), rather than the phase advance induced by $5 \mu \mathrm{M}$ DA (Fig. $2 D)$. The phase delay was sustained in both treatment groups (Fig. 10F), perhaps because other network neurons did not undergo changes in activity; for example, cycle period was not significantly altered in these experiments. Together with our previous findings (Figs. 2, 8, 9), these data suggested that tonic $5 \mathrm{~nm}$ DA enabled a mechanism whereby a decrease in LP burst duration triggered an increase in LP $I_{\mathrm{h}} G_{\text {max }}$, and contributed to phase recovery in $5 \mu \mathrm{M}$ DA.

\section{Discussion}

The pyloric network generates a rhythmic motor output with tightly maintained phase relationships (Marder and Bucher, 2007). We focused on one network neuron, the LP, which exclusively expresses type 1 DA receptors (D1Rs) (Zhang et al., 2010) and normally functions to set the upper limit on pyloric cycle frequency (Weaver and Hooper, 2003). We demonstrate that steady-state nanomolar DA enables an activity-dependent mechanism that can contribute to LP phase maintenance by persistently increasing $L P I_{\mathrm{h}} G_{\max }$. This mechanism (1) was triggered when there was a prolonged loss of LP network function, (2) may be evolutionarily conserved as loss of dopaminergic tone decreases $I_{\mathrm{h}}$ in rhythmically active globus pallidus neurons (Chan et al., 2011), and (3) may represent an adaptation to preserve motor network output with increasing dopaminergic neuronal activity.

\section{The slow phase recovery mechanism}

Application of tonic micromolar DA generated an LP phase advance. Phase recovered within $1 \mathrm{~h}$ despite the continued presence of DA. Two statistically significant changes in network activity occurred during the time window for phase recovery: an increase in pyloric cycle frequency and a decrease in LP burst duration. We did not investigate additional alterations in other network neurons, though all are directly modulated by micromolar DA (Flamm and Harris-Warrick, 1986b). The prolonged change in LP burst duration was necessary for phase recovery. We did not test whether the change in cycle frequency was also necessary. It is noteworthy that cycle period scales with LP burst duration across individuals (Goaillard et al., 2009), suggesting that a change in 
this ratio may trigger phase recovery. A decrease in LP burst duration elicited a persistent increase in LP $I_{\mathrm{h}} G_{\text {max }}$, but only in the presence of nanomolar DA. Phase recovery was always accompanied by a persistent increase in LP $I_{\mathrm{h}} G_{\max }$, and changes in $I_{\mathrm{h}}$ were necessary for phase recovery. The most parsimonious interpretation of the data is that tonic nanomolar DA permitted a change in LP burst duration to trigger a persistent increase in $L P I_{h}$ $G_{\max }$ that was necessary for LP phase recovery in $5 \mu \mathrm{M}$ DA.

It is possible that nanomolar DA coordinately regulates multiple currents in a given neuron to bring about phase recovery. Experimental and computational studies suggest that distinct conductance ratios are maintained in identified pyloric neurons, including the ratio of LP $I_{\mathrm{A}}$ to $I_{\mathrm{h}}$ (Schulz et al., 2006, 2007; Hudson and Prinz, 2010), and modulators are necessary for their maintenance (Khorkova and Golowasch, 2007). Interestingly, steadystate DA also regulates LP $I_{\mathrm{A}} G_{\max }$ (Rodgers et al., 2011).

\section{Dopaminergic systems are organized to prevent disruptions in the circuits they modulate}

The phase recovery mechanism may represent an adaptation to preserve motor network output with increasing dopaminergic neuronal activity. Dopaminergic systems use volume transmission, whereby phasically released DA diffuses out of open synapses (Descarries and Mechawar, 2000) and reuptake mechanisms are distantly distributed (Zoli et al., 1998), resulting in tonic DA in the extracellular space. Dopaminergic neuronal activity contributes to steady-state DA levels in conjunction with hormonal DA and DA transportermediated efflux (Borland and Michael, 2004; Moquin and Michael, 2011). As dopaminergic neuronal bursting increases, steadystate DA concentration should also increase, at least locally, thereby enabling the phase recovery mechanism. Continued dopaminergic neuron activity may then trigger the phase recovery mechanism by creating prolonged changes in network neuron activity. Thus, the $5 \mathrm{nM}$ DA treatment group shows a persistent LP phase advance that does not recover over $4 \mathrm{~h}$; whereas, prolonged micromolar DA triggers phase recovery over tens of minutes.

\section{Phase maintenance in the pyloric network}

Pyloric neuron phase relationships are partially determined by differential rates of PIR. Endogenous membrane currents strongly influence PIR (Rabbah and Nadim, 2005). $I_{\mathrm{A}}$ and $I_{\mathrm{h}}$ decrease and increase the rate of PIR, respectively (Tierney and Harris-Warrick, 1992, 1995a). An unknown slow conductance or combination of conductances shapes PIR according to activity averaged over a period of seconds (Hooper et al., 2009; Goaillard et al., 2010). In addition to endogenous currents, PIR is also influenced by the strength and timing of synaptic inhibition onto follower neurons (Eisen and Marder, 1984; Rabbah and Nadim, 2005, 2007).

Phase is well maintained in the pyloric network. Injecting current into the pacemaker to change cycle period does not alter
Before TTX

$15 \min$ in TTX

\section{LP}

IVn

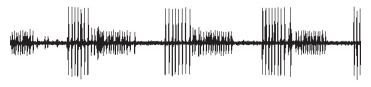

$p d n$
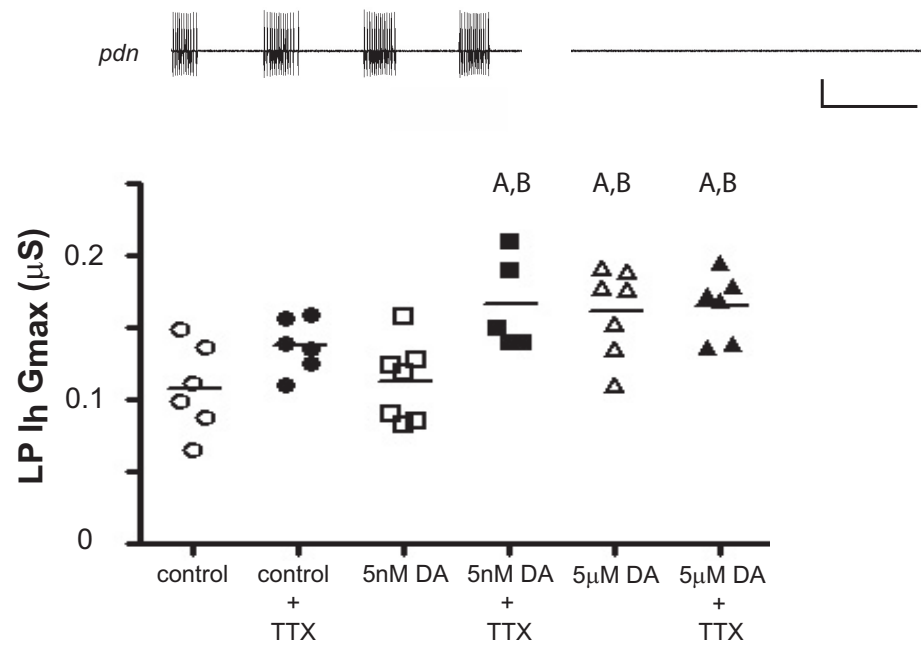

$A, B$

Figure 9. DA and decreased activity are both necessary to produce a significant increase in $L P I_{h} G_{\text {max }} \cdot A$, A typical $L P$ intracellular (im showing voltage trace over time and $/ v n$ and $p d n$ extracellular traces before and after TTX application for experiments

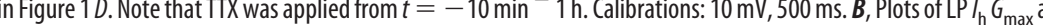
ost hoc analysis, $A$ denotes significant differences from control group, and $B$ denotes significant differences from $5 \mathrm{~nm}$ alone as A with a Tukey's post hoc test, $F_{(5,36)}=5.832, p=0.0007$.

neuronal phase (Hooper, 1997a,b), largely due to the dynamics of intrinsic conductances and synaptic depression (Hooper, 1998; Manor et al., 2003; Bose et al., 2004; Greenberg and Manor, 2005). Phase is also maintained across temperatures, due, in part, to the $\mathrm{Q}_{10}$ values of the channels mediating $I_{\mathrm{h}}$ and $I_{\mathrm{A}}$ (Tang et al., 2010). Our studies revealed an additional activity-dependent mechanism for phase maintenance that operated on a slow time scale (tens of minutes) and required dopaminergic tone.

\section{Phase homeostasis?}

A previous study demonstrated that neuronal phase was maintained in pyloric network output across individuals and throughout their lifetimes, prompting the authors to speculate that phase might be the target of a homeostat (Bucher et al., 2005). We did not prove the existence of a DA-enabled homeostat because bidirectional perturbations did not produce phase recovery (Davis, 2006). Perhaps the error signal detected by the homeostat sensor represents a complex set of changes that were not reproduced in all experiments. Alternatively, tonic DA may not enable a true homeostat, because phase is a network property whose maintenance requires coordinated changes across neurons. DA could provide this coordination by enabling multiple cell-specific compensatory mechanisms to explicitly redress the alterations induced by prolonged phasic DA.

An emergent idea in the field of activity-dependent homeostasis is that homeostatic mechanisms are active only at specific developmental stages and/or in certain cells (Turrigiano, 2011). Our findings might suggest that all cells possess a similar menu of recovery mechanisms that are differentially enabled by distinct modulators. Modulator enabling imparts flexibility; it allows a given neuron to maintain multiple states depending upon the 
A
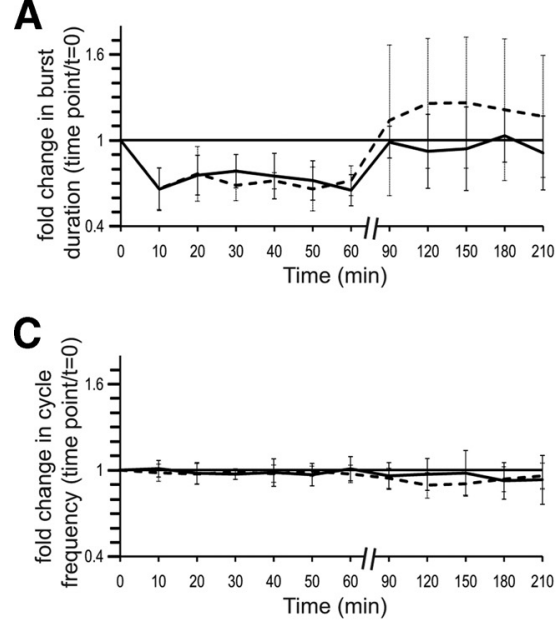

E

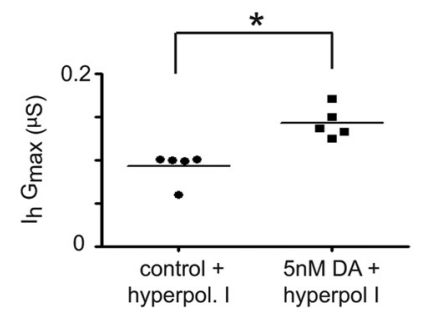

B

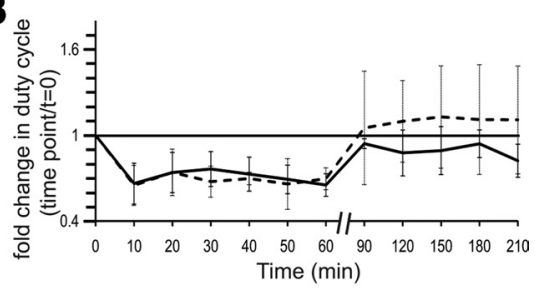

D 올

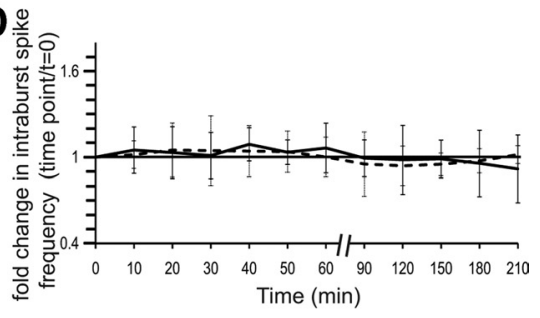

$\mathbf{F}$

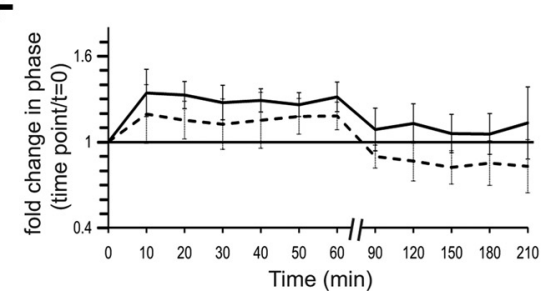

Figure 10. $5 \mathrm{~nm}$ DA permits a decrease in LP burst duration to trigger an increase in $L P I_{h} G_{\max }$. The experiments in Figure $1 D$ were performed for control and $5 \mathrm{~nm}$ DA treatment groups, but hyperpolarizing current (hyperpol I) was injected into the LP from $t=0-1$ h. $\boldsymbol{A}-\boldsymbol{D}$, Current injection reduced LP burst duration $(\boldsymbol{A})$ and duty cycle $(\boldsymbol{B})$ to the same extent in control and $5 \mathrm{~nm}$ preparations, but had no effect on cycle frequency $(\boldsymbol{C})$ or intraburst spike frequency $(\boldsymbol{D})$. Solid lines represent fold changes for the $5 \mathrm{~nm}$ treatment groups (mean $\pm S D, n=5$ ). Dashed lines represent fold changes for the control treatment groups (mean \pm SD, $n=5$ ). $\boldsymbol{E}$, The decrease in burst duration produced an increase in $\mathrm{LP} I_{\mathrm{h}} G_{\max }$ in $5 \mathrm{~nm}$ preparations relative to control. *Significant difference, Student's $t$ test, $p=0.002$. F, Current injection produced a sustained average LP phase delay in both treatment groups. Solid line represents fold changes for the $5 \mathrm{~nm}$ treatment group (mean $\pm S D, n=5$ ). Dashed line represents fold changes for the control treatment group (mean $\pm S D, n=5$ ).

circumstances. This would be beneficial in several instances, such as network switching (Hooper and Moulins, 1989; Dickinson et al., 1990) or when a motor circuit can generate two stable outputs.

Recovery mechanisms engender preparation-to-preparation variability and raise the question of how differentially compensated circuits maintain similar outputs when conditions change (Marder, 2011). Our data suggest that the correct extracellular milieu might permit further changes in synaptic strength (Grashow et al., 2010) and/or ionic conductances to restore network function within tens of minutes.

\section{$I_{\mathrm{h}}$ function and plasticity}

Hyperpolarization activated, cyclic nucleotide gated (HCN) cation channels mediate $I_{\mathrm{h}}$ (Wahl-Schott and Biel, 2009). They operate at subthreshold levels and contribute to membrane potential, dendritic integration and temporal summation (Magee, 1999; Poolos et al., 2002; Angelo et al., 2007). HCN channels are also critical determinants of membrane resonance properties in several neurons, including pyloric (Narayanan and Johnston, 2007, 2008; Tohidi and Nadim, 2009; Zemankovics et al., 2010). Neurons have frequency preferences that allow them to oscillate at, and best respond to, a particular frequency, termed the resonance frequency (Hutcheon and Yarom, 2000). Resonance frequency depends upon the low- and high-pass filtering properties of the membrane. High pass filters are generated by slowly activating currents that oppose changes in membrane potential, such as $I_{\mathrm{h}}$ (Hutcheon and Yarom, 2000).

$I_{\mathrm{h}}$ shows a high degree of plasticity. Chronic changes in activity, seizures and sensory deprivation can persistently alter $I_{\mathrm{h}}$ expression (Brewster et al., 2002; Gibson et al., 2006; Arimitsu et al., 2009; Hassfurth et al., 2009). Changes in $I_{\mathrm{h}}$ accompany LTP and LTD (van Welie et al., 2004; Fan et al., 2005; Brager and Johnston, 2007; Campanac et al., 2008), and it has been suggested that $I_{\mathrm{h}}$ is an effector for activity-dependent homeostatic plasticity (Narayanan and Johnston, 2010). Resonance frequency is variable in CA1 pyramidal neurons such that the increase in $I_{\mathrm{h}}$ that accompanied LTP increased resonance frequency, suggesting that neurons may tune their resonance frequencies to the inputs they receive (Narayanan and Johnston, 2007).

We hypothesize that the increase in LP $I_{\mathrm{h}} G_{\max }$ could retune LP resonance frequency to match an increase in pacemaker cycle frequency. The LP neuron receives rhythmic inhibition from the pacemaker, and provides the pacemaker with reciprocal feedback inhibition (Fig. 1C). Pyloric cycle frequency, which correlates with pacemaker resonance frequency (Tohidi and Nadim, 2009), is significantly increased in micromolar DA. LP may retune its resonance frequency to match the pacemaker to maintain network functionality, as the efficacy of LP feedback inhibition depends on pacemaker phase (Thirumalai et al., 2006). Indeed, LP cannot establish an upper limit on network cycle frequency in prolonged micromolar DA, because the phase relationship between LP and the pacemaker is distorted, causing LP synaptic inhibition onto the pacemaker to occur when the pacemaker is less sensitive to inhibition (Johnson et al., 2011). Alternatively changes in LP $I_{\mathrm{h}}$ may alter the strength of the PD synapse onto LP. Previous work in the pyloric circuit suggests $I_{\mathrm{h}}$ may act postsynaptically to control synaptic strength (Goeritz et al., 2011). Additionally, LP activity may be mostly synaptically driven, as it has a much slower burst frequency when isolated from pyloric pacemaker input (Bal et al., 1988).

Activity-dependent regulation of $\mathrm{HCN}$ channels occurs at multiple levels including transcription (Brewster et al., 2002; Fan et al., 2005), trafficking (Bender et al., 2007; Shin and Chetkovich, 2007; Hardel et al., 2008; Noam et al., 2010), and heteromerization (Zha et al., 2008). In dendrites, activity-dependent trafficking of $\mathrm{HCN}$ channels involves $\mathrm{Ca}^{2+}$ and CaMKII (Shin and Chetkovich, 2007; Noam et al., 2010). Depletion of $\mathrm{Ca}^{2+}$ stores and a concomitant increase in cytosolic $\mathrm{Ca}^{2+}$ can also increase HCN surface expression perisomatically (Narayanan et al., 2010). We have previously shown that steady-state nanomolar DA can regulate LP $I_{\mathrm{A}} G_{\max }$ through a translation-dependent, activityindependent mechanism mediated by target of rapamycin (TOR) (Rodgers et al., 2011). Reductions in LP burst duration may modulate this pathway. Many changes in protein expression accompanying LTP and LTD rely on TOR and are triggered by DA and changes 
in activity (Hoeffer and Klann, 2010). Whether changes in LP $I_{\mathrm{h}}$ are local or global, and the molecular mechanisms involved, are important topics for future studies.

\section{References}

Angelo K, London M, Christensen SR, Häusser M (2007) Local and global effects of $I(\mathrm{~h})$ distribution in dendrites of mammalian neurons. J Neurosci 27:8643-8653.

Arimitsu T, Nuriya M, Ikeda K, Takahashi T, Yasui M (2009) Activitydependent regulation of $\mathrm{HCN} 1$ protein in cortical neurons. Biochem Biophys Res Commun 387:87-91.

Bal T, Nagy F, Moulins M (1988) The pyloric central pattern generator in crustacea: a set of conditional neuronal oscillators. J Comp Physiol A Neuroethol Sens Neural Behav Physiol 163:715-727.

Bender RA, Kirschstein T, Kretz O, Brewster AL, Richichi C, Rüschenschmidt C, Shigemoto R, Beck H, Frotscher M, Baram TZ (2007) Localization of HCN1 channels to presynaptic compartments: novel plasticity that may contribute to hippocampal maturation. J Neurosci 27:4697-4706.

Borland LM, Michael AC (2004) Voltammetric study of the control of striatal dopamine release by glutamate. J Neurochem 91:220-229.

Bose A, Manor Y, Nadim F (2004) The activity phase of postsynaptic neurons in a simplified rhythmic network. J Comput Neurosci 17:245-261.

Brager DH, Johnston D (2007) Plasticity of intrinsic excitability during long-term depression is mediated through mGluR-dependent changes in $I(\mathrm{~h})$ in hippocampal CA1 pyramidal neurons. J Neurosci 27:13926-13937.

Brewster A, Bender RA, Chen Y, Dube C, Eghbal-Ahmadi M, Baram TZ (2002) Developmental febrile seizures modulate hippocampal gene expression of hyperpolarization-activated channels in an isoform- and cellspecific manner. J Neurosci 22:4591-4599.

Bucher D, Prinz AA, Marder E (2005) Animal-to-animal variability in motor pattern production in adults and during growth. J Neurosci 25:1611-1619.

Burgess N, Barry C, O’Keefe J (2007) An oscillatory interference model of grid cell firing. Hippocampus 17:801-812.

Campanac E, Daoudal G, Ankri N, Debanne D (2008) Downregulation of dendritic $I(\mathrm{~h})$ in CA1 pyramidal neurons after LTP. J Neurosci 28:8635-8643.

Chan CS, Glajch KE, Gertler TS, Guzman JN, Mercer JN, Lewis AS, Goldberg AB, Tkatch T, Shigemoto R, Fleming SM, Chetkovich DM, Osten P, Kita H, Surmeier DJ (2011) HCN channelopathy in external globus pallidus neurons in models of Parkinson's disease. Nat Neurosci 14:85-92.

Davis GW (2006) Homeostatic control of neural activity: from phenomenology to molecular design. Annu Rev Neurosci 29:307-323.

Descarries L, Mechawar N (2000) Ultrastructural evidence for diffuse transmission by monoamine and acetylcholine neurons of the central nervous system. Prog Brain Res 125:27-47.

Dickinson PS, Mecsas C, Marder E (1990) Neuropeptide fusion of two motor-pattern generator circuits. Nature 344:155-158.

Eisen JS, Marder E (1984) A mechanism for production of phase shifts in a pattern generator. J Neurophysiol 51:1375-1393.

Fan Y, Fricker D, Brager DH, Chen X, Lu HC, Chitwood RA, Johnston D (2005) Activity-dependent decrease of excitability in rat hippocampal neurons through increases in I(h). Nat Neurosci 8:1542-1551.

Flamm RE, Harris-Warrick RM (1986a) Aminergic modulation in lobster stomatogastric ganglion. I. Effects on motor pattern and activity of neurons within the pyloric circuit. J Neurophysiol 55:847-865.

Flamm RE, Harris-Warrick RM (1986b) Aminergic modulation in lobster stomatogastric ganglion. II. Target neurons of dopamine, octopamine, and serotonin within the pyloric circuit. J Neurophysiol 55:866-881.

Fuxe K, Dahlstrom AB, Jonsson G, Marcellino D, Guescini M, Dam M, Manger P, Agnati L (2010) The discovery of central monoamine neurons gave volume transmission to the wired brain. Prog Neurobiol 90:82-100.

Gibson JR, Bartley AF, Huber KM (2006) Role for the subthreshold currents ILeak and IH in the homeostatic control of excitability in neocortical somatostatin-positive inhibitory neurons. J Neurophysiol 96:420-432.

Goaillard JM, Taylor AL, Schulz DJ, Marder E (2009) Functional consequences of animal-to-animal variation in circuit parameters. Nat Neurosci 12:1424-1430.

Goaillard JM, Taylor AL, Pulver SR, Marder E (2010) Slow and persistent postinhibitory rebound acts as an intrinsic short-term memory mechanism. J Neurosci 30:4687-4692.
Goeritz ML, Ouyang Q, Harris-Warrick RM (2011) Localization and function of Ih channels in a small neural network. J Neurophysiol 106:44-58.

Grace AA (1991) Phasic versus tonic dopamine release and the modulation of dopamine system responsivity: a hypothesis for the etiology of schizophrenia. Neuroscience 41:1-24.

Grace AA (1995) The tonic/phasic model of dopamine system regulation: its relevance for understanding how stimulant abuse can alter basal ganglia function. Drug Alcohol Depend 37:111-129.

Grashow R, Brookings T, Marder E (2010) Compensation for variable intrinsic neuronal excitability by circuit-synaptic interactions. J Neurosci 30:9145-9156.

Greenberg I, Manor Y (2005) Synaptic depression in conjunction with A-current channels promote phase constancy in a rhythmic network. J Neurophysiol 93:656-677.

Hardel N, Harmel N, Zolles G, Fakler B, Klöcker N (2008) Recycling endosomes supply cardiac pacemaker channels for regulated surface expression. Cardiovasc Res 79:52-60.

Harris-Warrick RM, Coniglio LM, Barazangi N, Guckenheimer J, Gueron S (1995a) Dopamine modulation of transient potassium current evokes phase shifts in a central pattern generator network. J Neurosci 15:342-358.

Harris-Warrick RM, Coniglio LM, Levini RM, Gueron S, Guckenheimer J (1995b) Dopamine modulation of two subthreshold currents produces phase shifts in activity of an identified motoneuron. J Neurophysiol 74:1404-1420.

Hassfurth B, Magnusson AK, Grothe B, Koch U (2009) Sensory deprivation regulates the development of the hyperpolarization-activated current in auditory brainstem neurons. Eur J Neurosci 30:1227-1238.

Heitler WJ (2009) Practical tools for analysing rhythmic neural activity. J Neurosci Methods 185:151-164.

Hoeffer CA, Klann E (2010) mTOR signaling: at the crossroads of plasticity, memory and disease. Trends Neurosci 33:67-75.

Hooper SL (1997a) Phase maintenance in the pyloric pattern of the lobster (Panulirus interruptus) stomatogastric ganglion. J Comput Neurosci 4:191-205.

Hooper SL (1997b) The pyloric pattern of the lobster (Panulirus interruptus) stomatogastric ganglion comprises two phase-maintaining subsets. J Comput Neurosci 4:207-219.

Hooper SL (1998) Transduction of temporal patterns by single neurons. Nat Neurosci 1:720-726.

Hooper SL, Moulins M (1989) Switching of a neuron from one network to another by sensory-induced changes in membrane properties. Science 244:1587-1589.

Hooper SL, Buchman E, Weaver AL, Thuma JB, Hobbs KH (2009) Slow conductances could underlie intrinsic phase-maintaining properties of isolated lobster (Panulirus interruptus) pyloric neurons. J Neurosci 29:1834-1845.

Hudson AE, Prinz AA (2010) Conductance ratios and cellular identity. PLoS Comput Biol 6:e1000838.

Hutcheon B, Yarom Y (2000) Resonance, oscillation and the intrinsic frequency preferences of neurons. Trends Neurosci 23:216-222.

Jing J, Weiss KR (2002) Interneuronal basis of the generation of related but distinct motor programs in Aplysia: implications for current neuronal models of vertebrate intralimb coordination. J Neurosci 22:6228-6238.

Johnson BR, Brown JM, Kvarta MD, Lu JY, Schneider LR, Nadim F, HarrisWarrick RM (2011) Differential modulation of synaptic strength and timing regulate synaptic efficacy in a motor network. J Neurophysiol 105:293-304.

Khorkova O, Golowasch J (2007) Neuromodulators, not activity, control coordinated expression of ionic currents. J Neurosci 27:8709-8718.

Kiehn O, Harris-Warrick RM (1992) 5-HT modulation of hyperpolarizationactivated inward current and calcium-dependent outward current in a crustacean motor neuron. J Neurophysiol 68:496-508.

Magee JC (1999) Dendritic lh normalizes temporal summation in hippocampal CA1 neurons. Nat Neurosci 2:508-514.

Manor Y, Bose A, Booth V, Nadim F (2003) Contribution of synaptic depression to phase maintenance in a model rhythmic network. J Neurophysiol 90:3513-3528.

Marder E (2011) Variability, compensation, and modulation in neurons and circuits. Proc Natl Acad Sci U S A 108 [Suppl 3]:15542-15548.

Marder E, Bucher D (2007) Understanding circuit dynamics using the stomatogastric nervous system of lobsters and crabs. Annu Rev Physiol 69:291-316 
Moquin KF, Michael AC (2011) An inverse correlation between the apparent rate of dopamine clearance and tonic autoinhibition in subdomains of the rat striatum: a possible role of transporter-mediated dopamine efflux. J Neurochem 117:133-142.

Narayanan R, Johnston D (2007) Long-term potentiation in rat hippocampal neurons is accompanied by spatially widespread changes in intrinsic oscillatory dynamics and excitability. Neuron 56:1061-1075.

Narayanan R, Johnston D (2008) The h channel mediates location dependence and plasticity of intrinsic phase response in rat hippocampal neurons. J Neurosci 28:5846-5860.

Narayanan R, Johnston D (2010) The h current is a candidate mechanism for regulating the sliding modification threshold in a BCM-like synaptic learning rule. J Neurophysiol 104:1020-1033.

Narayanan R, Dougherty KJ, Johnston D (2010) Calcium store depletion induces persistent perisomatic increases in the functional density of $h$ channels in hippocampal pyramidal neurons. Neuron 68:921-935.

Noam Y, Zha Q, Phan L, Wu RL, Chetkovich DM, Wadman WJ, Baram TZ (2010) Trafficking and surface expression of hyperpolarization-activated cyclic nucleotide-gated channels in hippocampal neurons. J Biol Chem 285:14724-14736.

Oginsky MF, Rodgers EW, Clark MC, Simmons R, Krenz WD, Baro DJ (2010) $\mathrm{D}(2)$ receptors receive paracrine neurotransmission and are consistently targeted to a subset of synaptic structures in an identified neuron of the crustacean stomatogastric nervous system. J Comp Neurol 518:255-276.

Poolos NP, Migliore M, Johnston D (2002) Pharmacological upregulation of h-channels reduces the excitability of pyramidal neuron dendrites. Nat Neurosci 5:767-774.

Rabbah P, Nadim F (2005) Synaptic dynamics do not determine proper phase of activity in a central pattern generator. J Neurosci 25:11269-11278.

Rabbah P, Nadim F (2007) Distinct synaptic dynamics of heterogeneous pacemaker neurons in an oscillatory network. J Neurophysiol 97:2239-2253.

Rodgers EW, Krenz WD, Baro DJ (2011) Tonic dopamine induces persistent changes in the transient potassium current through translational regulation. J Neurosci 31:13046-13056.

Rutishauser U, Ross IB, Mamelak AN, Schuman EM (2010) Human memory strength is predicted by theta-frequency phase-locking of single neurons. Nature 464:903-907.

Schultz W (2007) Multiple dopamine functions at different time courses. Annu Rev Neurosci 30:259-288.

Schulz DJ, Goaillard JM, Marder E (2006) Variable channel expression in identified single and electrically coupled neurons in different animals. Nat Neurosci 9:356-362.

Schulz DJ, Goaillard JM, Marder EE (2007) Quantitative expression profiling of identified neurons reveals cell-specific constraints on highly variable levels of gene expression. Proc Natl Acad Sci U S A 104:13187-13191.

Selverston AI, Russell DF, Miller JP (1976) The stomatogastric nervous system: structure and function of a small neural network. Prog Neurobiol $7: 215-290$.
Selverston AI, Moulins M, eds (1987) The crustacean stomatogastric system. Berlin: Springer.

Shin M, Chetkovich DM (2007) Activity-dependent regulation of h channel distribution in hippocampal CA1 pyramidal neurons. J Biol Chem 282:33168-33180.

Stein W (2009) Modulation of stomatogastric rhythms. J Comp Physiol A Neuroethol Sens Neural Behav Physiol 195:989-1009.

Tang LS, Goeritz ML, Caplan JS, Taylor AL, Fisek M, Marder E (2010) Precise temperature compensation of phase in a rhythmic motor pattern. PLoS Biol 8:e1000469.

Thirumalai V, Prinz AA, Johnson CD, Marder E (2006) Red pigment concentrating hormone strongly enhances the strength of the feedback to the pyloric rhythm oscillator but has little effect on pyloric rhythm period. J Neurophysiol 95:1762-1770.

Tierney AJ, Harris-Warrick RM (1992) Physiological role of the transient potassium current in the pyloric circuit of the lobster stomatogastric ganglion. J Neurophysiol 67:599-609.

Tohidi V, Nadim F (2009) Membrane resonance in bursting pacemaker neurons of an oscillatory network is correlated with network frequency. J Neurosci 29:6427-6435.

Turrigiano G (2011) Too many cooks? Intrinsic and synaptic homeostatic mechanisms in cortical circuit refinement. Annu Rev Neurosci 34:89-103.

van Welie I, van Hooft JA, Wadman WJ (2004) Homeostatic scaling of neuronal excitability by synaptic modulation of somatic hyperpolarizationactivated Ih channels. Proc Natl Acad Sci U S A 101:5123-5128.

Wahl-Schott C, Biel M (2009) HCN channels: structure, cellular regulation and physiological function. Cell Mol Life Sci 66:470-494.

Weaver AL, Hooper SL (2003) Follower neurons in lobster (Panulirus interruptus) pyloric network regulate pacemaker period in complementary ways. J Neurophysiol 89:1327-1338.

Weaver AL, Roffman RC, Norris BJ, Calabrese RL (2010) A role for compromise: synaptic inhibition and electrical coupling interact to control phasing in the leech heartbeat CpG. Front Behav Neurosci 4:38.

Zemankovics R, Káli S, Paulsen O, Freund TF, Hájos N (2010) Differences in subthreshold resonance of hippocampal pyramidal cells and interneurons: the role of h-current and passive membrane characteristics. J Physiol 588:2109-2132.

Zha Q, Brewster AL, Richichi C, Bender RA, Baram TZ (2008) Activitydependent heteromerization of the hyperpolarization-activated, cyclicnucleotide gated $(\mathrm{HCN})$ channels: role of $\mathrm{N}$-linked glycosylation. J Neurochem 105:68-77.

Zhang H, Rodgers EW, Krenz WD, Clark MC, Baro DJ (2010) Cell specific dopamine modulation of the transient potassium current in the pyloric network by the canonical D1 receptor signal transduction cascade. J Neurophysiol 104:873-884.

Zoli M, Torri C, Ferrari R, Jansson A, Zini I, Fuxe K, Agnati LF (1998) The emergence of the volume transmission concept. Brain Res Brain Res Rev 26:136-147. 